\title{
Sociedade Cooperativa: paradigma de participação no mercado concorrencial
}

\author{
José Eduardo Miranda \\ Doutorando em Direito, Professor Universitário, Vice-Diretor da Faculdade de Aracruz \\ Andréa Corrêa Lima \\ Doutoranda em Direito, Professora e Coordenadora \\ do Departamento de Ciências Jurídicas da Faculdade de Aracruz
}

Lo más inteligente para impedir un daño es evitar su causa.

(Javier Divar) ${ }^{1}$

\section{Considerações iniciais}

Observada a recente edição do Código Civil brasileiro, e considerando as altercações provocadas na regulamentação das sociedades em geral, merece assinalar a permanência de um dualismo interpretativo acerca do posicionamento das sociedades cooperativas na órbita dos entes jurídicos exercentes das atividades negociais.

Visto o rigorismo da le ${ }^{2}$, os estudiosos tradicionais preservam características primitivas e não exitam em classificar a sociedade cooperativa como sociedade simples, haja vista as peculiaridades que lhe são próprias.

1 DIVAR, Javier: La alternativa cooperativa: una respuesta ante la crisis. Barcelona: Ceac (1985), p. 34.

2 Aquí, convém destacar que a sociedade cooperativa resguarda-se distante da empresarialidade única e exclusivamente em decorrência do determinismo legal. Seu estado é antagônico ao da sociedade anônima, considerada empresária (comercial), independentemente do objeto (Veja-se em EstreLA, Hernani: Curso de direito comercial. Rio de Janeiro:José Konfino, 1973. p.396 e 471). 
Não obstante, deve-se anotar que as novéis dinâmicas de atuação de mercado e a moderna classificação do agente ativo dos negócios que operam resultado econômico dilatam o campo de visão dos investigadores, e permitem o enquadramento da sociedade cooperativa no universo das sociedades empresariais.

Desta forma, e considerando que as sociedades cooperativas ocupam importante posto como instrumento associativo voluntário dirigido ao equilíbrio sócio-econômico de um mundo em constante crise ${ }^{3}$, se entende necessário estabilizar o liame de compreensão, de maneira que uma ou outra corrente não impeça o necessário desenvolvimento e modernização da sociedade cooperativa.

Assim sendo, e com soberano respeito aos entendimentos contrários, o presente trabalho será utilizado para apresentar os alicerces que sustentam a sociedade cooperativa como ente jurídico dotado de empresarialidade, de forma que sua atuação negocial sirva de modelo para as demais entidades que participam do mercado concorrencial.

Com empenho na preleção didática, a proposta se desenvolverá em três apartados distintos, porém inter-relacionados, quais sejam: o código civil brasileiro e as atividades de mercado: as atividades empresárias e as atividades não empresárias; a sociedade cooperativa como exercente das atividades de mercado: a sociedade cooperativa empresário; e, sociedade cooperativa e mercado concorrencial: o paradigma a ser seguido.

\section{O Código Civil brasileiro e as atividades de mercado: as atividades empresárias e as atividades não empresárias}

Ao sinalizar que o termo atividade significa atuação, ação, agir, merece relevo o fato singular de que é justamente da atividade humana que surgem os bens e serviços que satisfazem diferentes necessidades de mercado 4 .

3 MiRAndA, José Eduardo S.: «La financiación de la sociedad cooperativa». Boletín da la Asociación Internacional de Derecho Cooperativo, Bilbao: Universidad de Deusto (2003), p. 232.

4 MARIANI, Irineu: «Direito da empresa, atividade empresarial, empresa e empresário (à luz do novo código civil)». Revista Magister de Direito Empresarial. 08, AbrilMaio/2006, Porto Alegre: Magister (2006), p. 23. 
Neste contexto, e considerada a inserção privatista do agir economicamente, há de se considerar que o Código Civil de 2002 formalizou o ingresso da teoria dos atos da empresa no âmago do sistema jurídico pátrio, e estabeleceu o Direito da Empresa como responsável pela sistematização das atividades ditas de mercado.

Seqüentes na trilha de identificação estabelecida pelo legislador civilista, se pode observar que o elemento empresarial da atividade de mercado resulta da identificação do núcleo do exercício econômico profissional do empresário ${ }^{5}$.

Neste sentido, o caput do artigo 966 do Código Civil outorga empresarialidade a toda «atividade econômica organizada para a produção ou circulação de bens ou de serviços» ${ }^{6}$.

Pelo texto do dispositivo se é possível perceber que longe de um manifesto enumerativo e limitador do ato empresarial, o legislador civilista se mostra abrangente, e sub-roga a empresarialidade ao fator econômico-organizacional de toda performance profissional que viabilize tanto a produção como a circulação de bens ou de serviços ${ }^{7}$.

Com suporte na dualidade dos elementos definidores do exercício da ação profissional, urge manifestar, primeiro, que a atividade é econômica, em razão de se desenvolver com método econômico, que permite ao exercente subtrair, no mínimo, os importes necessários para a cobertura dos gastos com a manutenção e desenvolvimento da empresa; e, segundo, que a organização diz respeito à planificação, ao programa racional sobre o qual se contemplam aspectos pessoaistécnicos-econômicos ao exercício da atividade empresarial ${ }^{8}$.

5 ROJO sublinha que a atividade do empresário se trata de «uma actividad para el mercado em cuanto que está dirigida a la satisfacción de necesidades de terceros. No es concebible un empresario sin la existencia del Mercado: la actividad de producción o de distribución de bienes o de servicios se organiza en función de un mercado concreto, que, en definitiva, determinará el éxito o el fracaso del empresario. Es indiferente que el empresario tenga varios clientes o que sólo trabaje para uno. En ambos casos la actividad se realiza para el mercado en la medida en que está dirigida a la satisfacción de necesidades ajenas» (Roso, Angél: «El empresario». In MenÉnDEZ, Aurélio: Lecciones de derecho mercantil. Madrid: Civitas (2003), p. 43).

6 Vade Mecum Saraiva: Código Civil. São Paulo: Saraiva (2007), p. 236.

7 A empresarialidade não deriva da classe da atividade levada a termo pelo empresário, mas sim do modo pelo qual ela é exercida.

8 Roso: op. cit., p. 43. 
Diferente do que fez no caput, ao longo do parágrafo único do artigo 966 do Código Civil, o legislador age por exclusão e determina que não são empresárias as atividades profissionais de cunho intelectual, sejam as de natureza científica, literária ou artística, "salvo se o exercício da profissão constituir elemento de empresa» ${ }^{9}$.

Sob este enfoque, repousa importante sublinhar que a ausência da empresarialidade não resulta do exercício profissional da atividade intelectual, mas da insuficiência do fator econômico-organizacional do desempenho, constitutivo daquilo que a segunda parte do parágrafo único do artigo 966 chama de elemento de empresa, ou, conforme se entende, elemento da própria atividade empresarial.

Portanto, não há de se indagar como empresária a atividade levada a termo pelo profissional das ciências, das artes ou da literatura, se a ação empreendida perece da conjugação de feições pessoais-técnicos-econômicos e tem como escopo a subtração dos meios indispensáveis ao sustento do exercente.

\section{A sociedade cooperativa como exercente das atividades de mercado: a sociedade cooperativa empresário}

Para aproximar a sociedade cooperativa do perfil empresarial, se mostra fundamental reeditar que a Aliança Cooperativa Internacional, pela Declaração da Identidade Cooperativa formulada no Congresso de Manchester, em setembro de 1995, estabeleceu que a cooperativa é uma associação de pessoas que se unem de forma voluntária para satisfazer suas necessidades e aspirações econômicas, sociais e culturais em comum, mediante uma empresa de propriedade conjunta e gestão democrática ${ }^{10}$.

9 É oportuno colacionar que o parágrafo único do artigo 966, expressa literalmente que «não se considera empresário quem exerce profissão intelectual, de natureza científica, literária ou artística, ainda com o concurso de auxiliares ou colaboradores, salvo se o exercício da profissão constituir elemento de empresa» (VADE MECUM Saraiva: Código Civil. São Paulo: Saraiva (2007), p. 236).

10 ICA: «Declaración de la Alianza Cooperativa Internacional sobre la Identidad Cooperativa», in InstiTUto De Estudios Cooperativos: Anuario de estudios cooperativos. Bilbao: Universidad de Deusto (1995), p. 73. 
A partir do preceito conceitual coorporativo ajustado pelo órgão máximo do Cooperativismo Global ${ }^{11}$, e tendo em vista que o Código Civil brasileiro deixa evidente que o fator econômico-organizacional constitui-se no elemento intrínseco da atividade empresária, tem-se que esta importa na identificação verdadeira do significado de empresa ${ }^{12}$, -componente precípuo da definição de cooperativa.

Sob esta ótica, e ao considerar-se que as atividades de mercado são, na sua essência, atividades empresariais, restou demonstrado que as exigências destas atividades determinam a presença de um sujeito peculiar em relação aos demais sujeitos de direito ${ }^{13}$, clamam pela consecução de métodos econômicos próprios ao exercício da atividade, e impõe o levante de princípios inerentes à peculiaridade do exercício profissional14

Desta forma, e ao considerar-se que na esfera empresarial o desenvolvimento profissional da atividade econômica organizada é a razão imperiosa que outorga ao seu exercente o status de empresário, é evidente que a sociedade cooperativa se enquadra neste perfil, tendo em vista ser constituida para a exploração de atividades econômicas no âmbito do mercado, de forma profissional e organizada ${ }^{15}$.

Em puridade técnica, a sociedade cooperativa deve ser considerada uma fórmula jurídica para a organização econômica, sujeita aos princípios e fins que são específicos e que têm a mesma extensão técnica e econômica que podem ter as sociedades empresárias ${ }^{16}$.

11 Se diz conceito coorporativo pela aplicação uniforme da definição de cooperativa em todos os seguimentos cooperativos do Globo.

12 De forma sintética, é o mesmo que manifestar que empresa é a atividade econômica desenvolvida organizativamente pelo empresário.

13 Recorde-se que o próprio capuz do artigo 966 estabeleceu que é o empresário que desenvolve atividades empresárias, quais sejam, as atividades econômicas, organizadas para o mercado.

14 GADEA, Enrique: «Consideracines para la delimitación de la sociedad cooperativa», in Facultad De Derecho: Evolución del escenario económico. Transformaciones estructurales en el actual escenario económico y sus proyecciones de futuro. Bilbao: Universidad de Deusto (1996), p. 179.

15 «Si en el orden jurídico mercantil la empresa es una determinada forma de actividad económica organizada, es obvio que toda empresa necesita un sujeto que organice y ejercite esa actividad. Como hemos dicho anteriormente, ese sujeto es el empresario: persona física o jurídica que por si o por medio de delegados ejercita y desarrolla en nombre propio una actividad en el mercado constitutiva de empresa, adquiriendo la titularidad de las obligaciones y derechos nacidos de esa actividad» (MIRANDA: op. cit., p. 235).

16 Divar: op. cit., pp. 29 y 30. 
Como sujeito que organiza e dirige a empresa, a sociedade cooperativa titulariza os bens que se configuram para alcançar a plenitude do exercício de suas atividades ${ }^{17}$ e leva a máscara da empresarialidade.

O sustentáculo deste manifesto se encontra no fato peculiar de que a empresarialidade do sujeito, ou aptidão para converter-se em empresário deve depender única e exclusivamente da forma, do método ou da maneira como a atividade se desenvolve, uma vez que o centro de gravidade do sistema se deslocou do ato para a organização ${ }^{18}$.

Assim sendo, ao perceber-se que a exploração das atividades de mercado, se consuma de maneira habitual, organizada, e sob o manto de uma empresa que utiliza procedimentos indiscutivelmente empresariais, resta evidente que a sociedade cooperativa é um tipo de empresário social, um ente dotado de personalidade jurídica, titular do exercício de uma atividade econômica inerente à sua constituição.

\section{Sociedade cooperativa e mercado concorrencial: o paradigma a ser seguido}

ainda que as intenções honoráveis perfaçam o berço de uma educação calcada em princípio sublimes que alicercem virtudes diversificadas, "a cobiça, o egoísmo, o desejo de poder e de possuir ${ }^{19}{ }^{\text {» são pe- }}$ culiaridades próprias da natureza humana.

Ao observar que o afã de domínio e de benefício pessoal acompanha o homem desde que imprimiu seus primeiros passos pela trilha terrena, Divar anota que «para o humano, o bem geral somente parece ser bem enquanto possível, compreensível, por extensão, de seu próprio bem ${ }^{20}$ ».

Esta lição, de indelével sabedoria, reflete as principais técnicas comportamentais empreendidas pelos gestores das entidades jurídicas que buscam ocupar e manter um espaço no mercado concorrencial.

\footnotetext{
17 MIRANDA: op. cit., p. 236.

18 GADEA: op. cit., p. 179.

19 Divar: op. cit., p. 15.

20 Ibid: p. 15.
} 
Mesmo conscientes de que a competição econômica se mostra como um processo dialético, de diferenciação ininterrupta, tem-se observado que, para fortalecer o exercício de suas atividades e destacarem-se diante do público alvo de sua oferta, os agentes ativos das diferentes atividades econômicas superam a preocupação pelo preço justo e eqüitativo entre os concorrentes, qualidade do produto, disponibilidade nos pontos de venda e a imagem da qual o produto goza diante dos consumidores, e concentram suas energias mercadológicas na prática constante de atos determinantes da malsinada concorrência desleal ${ }^{21}$.

21 É fundamental anotar-se que o artigo 195, da 9.279/96, dispõe que: «Comete crime de concorrência desleal quem: I - publica, por qualquer meio, falsa afirmação, em detrimento de concorrente, com o fim de obter vantagem; II - presta ou divulga, acerca de concorrente, falsa informação, com o fim de obter vantagem; III - emprega meio fraudulento, para desviar, em proveito próprio ou alheio, clientela de outrem; IV - usa expressão ou sinal de propaganda alheios, ou os imita, de modo a criar confusão entre os produtos ou estabelecimentos; $V$ - usa, indevidamente, nome comercial, título de estabelecimento ou insígnia alheios ou vende, expõe ou oferece à venda ou tem em estoque produto com essas referências; VI - substitui, pelo seu próprio nome ou razão social, em produto de outrem, o nome ou razão social deste, sem o seu consentimento; VII - atribui-se, como meio de propaganda, recompensa ou distinção que não obteve; VIII - vende ou expõe ou oferece à venda, em recipiente ou invólucro de outrem, produto adulterado ou falsificado, ou dele se utiliza para negociar com produto da mesma espécie, embora não adulterado ou falsificado, se o fato não constitui crime mais grave; IX - dá ou promete dinheiro ou outra utilidade a empregado de concorrente, para que o empregado, faltando ao dever do emprego, the proporcione vantagem; $X$ - recebe dinheiro ou outra utilidade, ou aceita promessa de paga ou recompensa, para, faltando ao dever de empregado, proporcionar vantagem a concorrente do empregador; XI - divulga, explora ou utiliza-se, sem autorização, de conhecimentos, informações ou dados confidenciais, utilizáveis na indústria, comércio ou prestação de serviços, excluídos aqueles que sejam de conhecimento público ou que sejam evidentes para um técnico no assunto, a que teve acesso mediante relação contratual ou empregatícia, mesmo após o término do contrato; XII - divulga, explora ou utiliza-se, sem autorização, de conhecimentos ou informações a que se refere o inciso anterior, obtidos por meios ilícitos ou a que teve acesso mediante fraude; ou XIII - vende, expõe ou oferece à venda produto, declarando ser objeto de patente depositada, ou concedida, ou de desenho industrial registrado, que não o seja, ou menciona-o, em anúncio ou papel comercial, como depositado ou patenteado, ou registrado, sem o ser; XIV - divulga, explora ou utiliza-se, sem autorização, de resultados de testes ou outros dados não divulgados, cuja elaboração envolva esforço considerável e que tenham sido apresentados a entidades governamentais como condição para aprovar a comercialização de produtos. (VADE MeCUM SARAIVA: Lei 9.279/96. São Paulo: Saraiva, 2007. p. 1.546). 
Neste sentido, e com arrimo na especificidade que a legislação e a doutrina conferem à concorrência desleal22, não há como ocultar-se que a cooperação sistematizada se mostra o modelo essencial para fortalecer as atividades de mercado, uma vez que seu maior propósito é o de permitir o progresso, o bem-estar e a transformação do Homem.

Sublinha-se, assim, que ao diferenciar a cooperativa da empresa econômica comum, este objetivo se apresenta como o sustentáculo de um modelo empresarial, haja vista a contribuição que as cooperativas outorgam ao desenvolvimento de valores sociais e morais que elevam a vida humana sobre o que se revela puramente material e animal.

Ao revelar-se como o canal que aproxima a auto-gestão e a solidariedade do entorno onde se encontra inserida, a cooperativa traz no bojo de sua constituição a premissa de que a felicidade humana é a essência da produção e da circulação de bens e serviços.

Partindo-se deste princípio, e considerando-se que a felicidade está sub-rogada a um grau maior de complacência, a repudia ao supérfluo, ao desnecessário, e ao que lhe faz mal é comportamento próprio do Homem que almeja ser feliz.

Sob esta ótica, e contrariamente aos sócios de uma sociedade empresária-capitalista, os cooperados remetem o interesse especulativo para planos posteriores ${ }^{23}$ e buscam aproximar o "fazer cooperativo» das ações voltadas ao amparo de questões Humanas, seja as de cunho social, econômico, político, ambiental...24.

22 Importa sublinhar que COELHO classifica a concorrência desleal em específica e genérica. A primeira «se traduz pela tipificação penal de condutas lesivas aos direitos de propriedade intelectual titularizados por empresários» e, a segunda, "corresponde à responsabilidade extracontratual» (ULHOA, Fábio: Curso de direito comercial. V 1. 11 ed. São Paulo: Saraiva, 2007. pp. 192-193).

23 Importa registrar que independe de qualquer classificação, se empresária ou simples, a entidade cooperativa busca alcançar um resultado econômico, o que não fragiliza sua natureza.

24 O consagrado professor DIVAR leciona que «debe entenderse incompatible con el sistema cooperativo la producción con daño para la naturaleza, en cuanto que el medio ecológico y el hábitat natural son vitalísimos para conseguir una vida plenamente acorde a nuestro ser» (DIVAR: op. cit., p. 69). 
É por força deste aspecto que a sociedade cooperativa desponta como modelo ideal às práticas do mercado concorrencial!

O Homem Cooperativo, em decorrência dos valores inerentes ao cooperativismo, abdica, ou deveria abdicar, dos meios inidôneos que contaminam o exercício das atividades econômicas, e conforma sua atuação negocial mediante o desenvolvimento de uma postura equilibrada, transparente e honesta.

A auto-ajuda, a auto-responsabilidade, a democracia, a igualdade, a solidariedade, a honestidade, a transparência, a responsabilidade e a vocação social representam os alicerces da atuação empresarial-cooperativa, e servem de escudo contra a tendência pela competição desleal.

Destarte saber-se que a concorrência se mostre intrínseca ao mercado, a concorrência desenvolvida sob o manto da cooperação tende a ser justa, eis que a moral cooperativa ostenta a busca pela proeminência do verdadeiro sentido de dignidade, e faz prevalecer o respeito supremo à pessoa humana.

\section{Reflexão final}

Não há de se cogitar que a transmutação do perfil jurídico das entidades cooperativas derrogue sua raiz cooperacionista e sepulte o ideal transformador do Cooperativismo.

Ao contrário...

Vista a dinâmica das relações negociais, entende-se que a adequação da sociedade cooperativa, mediante o reconhecimento de sua condição de empresária, permitirá que o sistema cooperativo fortaleça seus alicerces e a estrutura cooperativa estabeleça o grau de credibilidade necessário ao trânsito pelo mercado concorrencial.

Neste sentido, entende-se que o Cooperativismo tanto alcançará o desígnio de proporcionar uma nobre forma de viver democraticamente, como encontrará o meio hábil à disseminação de seus valores no mundo dos negócios.

Verificada a importância do Homem no universo cooperativo, não há de se duvidar que a ação empresarial cooperativa possibilitará, ademais do fortalecimento da identidade cooperativa, o resgate da 
própria identidade do Homem, enquanto ser social que integra um meio em evolução permanente, e se mostra preocupado pela evolução do todo, do coletivo, incluídos aqueles que ainda não gozam das mínimas condições de atuar com liberdade, ética e profissionalismo pelos nebulosos caminhos do mercado concorrencial.

É sobre a base dos valores cooperativas que a competição do mercado se preservará justa, adequada às regras da concorrência legitima e viabilizadora da transformação total, que parte da mudança do Homem e alcança os câmbios sócio-econômicos necessários ao levante da qualidade de vida, do bem estar, das condições de igualdade, liberdade, dignidade, justiça e democracia. 